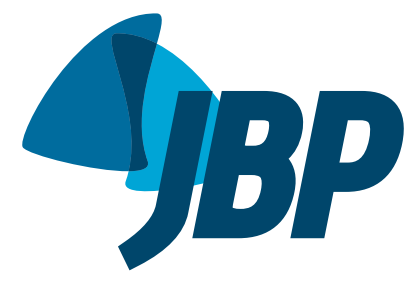

\title{
Inflammatory lung injury in rabbits: effects of high-frequency oscillatory ventilation in the prone position
}

\author{
Jose Roberto Fioretto ${ }^{1, a}$, Rafaelle Batistella Pires ${ }^{2, b}$, Susiane Oliveira Klefens ${ }^{1, c}$ \\ Cilmery Suemi Kurokawa ${ }^{1, \mathrm{~d}}$, Mario Ferreira Carpi ${ }^{1, \mathrm{e}}$, Rossano César Bonatto ${ }^{1, \mathrm{f}}$, \\ Marcos Aurélio Moraes ${ }^{1, \mathrm{~g}}$, Carlos Fernando Ronchi ${ }^{1,3, \mathrm{~h}}$
}

1. Disciplina de Pediatria, Faculdade de Medicina de Botucatu, Universidade Estadual Paulista - UNESP Botucatu (SP) Brasil.

2. Hospital de Reabilitação de Anomalias Craniofaciais, Universidade de São Paulo, Bauru (SP) Brasil.

3. Departamento de Fisioterapia, Universidade Federal de Uberlândia Uberlândia (MG) Brasil.

a. (ID) http://orcid.org/0000-0003-4034-5962

b. (iD http://orcid.org/0000-0002-3961-5534

c. (DD http://orcid.org/0000-0002-4988-8317

d. (iD http://orcid.org/0000-0003-1380-7527

e. (D) http://orcid.org0000-0002-1482-564X

f. (D) http://orcid.org/0000-0002-0648-876X

g. (D) http://orcid.org/0000-0003-0007-1506

h. (D) http://orcid.org/0000-0002-5927-9320

Submitted: 26 February 2018. Accepted: 12 August 2018

Study carried out in the Disciplina de Pediatria, Faculdade de Medicina de Botucatu, Universidade Estadual Paulista - UNESP - Botucatu (SP) Brasil.

\begin{abstract}
Objective: To compare the effects that prone and supine positioning during highfrequency oscillatory ventilation (HFOV) have on oxygenation and lung inflammation, histological injury, and oxidative stress in a rabbit model of acute lung injury (ALI). Methods: Thirty male Norfolk white rabbits were induced to ALI by tracheal saline lavage $\left(30 \mathrm{~mL} / \mathrm{kg}, 38^{\circ} \mathrm{C}\right.$ ). The injury was induced during conventional mechanical ventilation, and $\mathrm{ALI}$ was considered confirmed when a $\mathrm{PaO}_{2} / \mathrm{FiO}_{2}$ ratio $<100 \mathrm{mmHg}$ was reached. Rabbits were randomly divided into two groups: HFOV in the supine position (SP group, $n=15$ ); and HFOV with prone positioning (PP group, $n=15$ ). For HFOV, the mean airway pressure was initially set at $16 \mathrm{cmH}_{2} \mathrm{O}$. At 30,60 , and 90 min after the start of the HFOV protocol, the mean airway pressure was reduced to 14,12 , and $10 \mathrm{cmH}_{2} \mathrm{O}$, respectively. At $120 \mathrm{~min}$, the animals were returned to or remained in the supine position for an extra $30 \mathrm{~min}$. We evaluated oxygenation indices and histological lung injury scores, as well as TNF- $\alpha$ levels in BAL fluid and lung tissue. Results: After ALI induction, all of the animals showed significant hypoxemia, decreased respiratory system compliance, decreased oxygenation, and increased mean airway pressure in comparison with the baseline values. There were no statistically significant differences between the two groups, at any of the time points evaluated, in terms of the $\mathrm{PaO}_{2}$ or oxygenation index. However, TNF-a levels in BAL fluid were significantly lower in the PP group than in the SP group, as were histological lung injury scores. Conclusions: Prone positioning appears to attenuate inflammatory and histological lung injury during HFOV in rabbits with ALI.

Keywords: Respiration, artificial/adverse effects; Prone position; Lung/physiopathology; Pneumonia; Respiratory distress syndrome, adult; Acute lung injury; Disease models, animal; Rabbits.
\end{abstract}

\section{INTRODUCTION}

Acute respiratory distress syndrome (ARDS) is a heterogeneous syndrome with complex pathology and mechanisms. ${ }^{(1)}$ It is a life-threatening condition that is associated with high mortality, morbidity, and costs. ${ }^{(2-5)}$ The clinical management of ARDS is essentially supportive and includes optimized protective mechanical ventilation $(\mathrm{MV})$, the strategies of which should be directed at minimizing ventilator-induced lung injury, oxygen toxicity, and lung inflammation. ${ }^{(6)}$ In a recent study, Amato et al. ${ }^{(7)}$ found that decreases in driving pressure were strongly associated with increased survival in patients with ARDS. Therefore, high-frequency oscillatory ventilation (HFOV) is an attractive ventilatory method, ${ }^{(8,9)}$ because it involves the use of a lower tidal volume $\left(\mathrm{V}_{\mathrm{T}}, 1-3 \mathrm{~mL} / \mathrm{kg}\right)$ with an oscillatory frequency higher than that of physiological breathing $(5-10 \mathrm{~Hz})$, thus avoiding volume excursions and increases in alveolar pressure. During HFOV, a constant mean airway pressure (Paw) is applied in order to achieve and maintain alveolar recruitment, even at end-expiration. ${ }^{(10,11)}$
Despite the advantages of HFOV, the results of clinical studies have not supported its routine use. The recent Oscillation for Acute Respiratory Distress Syndrome Treated Early Trial ${ }^{(12)}$ was interrupted due to an increase in in-hospital mortality in the HFOV group. However, the patients in that group required more vasoactive support than did those in the control group, making it difficult to analyze the results. In two recent systematic reviews and meta-analyses, Meade et al. ${ }^{(13)}$ and Goligher et al. ${ }^{(14)}$ evaluated the use of HFOV in patients with ARDS. Meade et al. ${ }^{(13)}$ compared HFOV with protective conventional MV (CMV) in patients with ARDS and found mortality to be greater in the HFOV group patients than in the CMV group patients, although that effect varied depending on the severity of hypoxemia, lung injury apparently being greater among patients with mild or moderate ARDS, although mortality rates seemed to be lower among patients with severe ARDS. Goligher et al.(14) also analyzed HFOV in comparison with protective CMV, one study comparing HFOV with the use of a low $V_{T}$ and a high positive end-expiratory pressure (PEEP), and concluded that HFOV, used as in the studies conducted

Correspondence to:

Carlos Fernando Ronchi. Universidade Federal de Uberlândia, Rua Benjamin Constant, 1286, CEP 38400-678, Uberlândia, MG, Brasil.

Tel.: 5534 3218-2934. Fax: 5534 99950-6299. E-mail: fernando.ronchi@yahoo.com.br

Financial support: This study received financial support from the Fundação de Amparo à Pesquisa do Estado de São Paulo (FAPESP, São Paulo Research

Foundation; Grant no. 2010/06242-8) 
to date, provides no mortality benefit in comparison with protective CMV and may even be harmful in comparison with the use of a low $V_{T}$ with a high PEEP.

As an adjuvant therapy, prone positioning optimizes lung recruitment and ventilation-perfusion matching. ${ }^{(15,16)}$ In the prone position, lung perfusion is more evenly distributed, which improves ventilation to the dorsal areas of the lungs, thus improving perfusion. ${ }^{(17,18)}$ In addition, prone positioning lessens alveolar overdistension $^{(19)}$ and cyclic alveolar collapse, as well as reducing ventilator-induced lung injury, ${ }^{(20)}$ redirecting the compressive forces exerted by the weight of the heart on the lungs, ${ }^{(21)}$ and improving the drainage of secretions. ${ }^{(22)}$

In the Prone Positioning in Severe Acute Respiratory Distress Syndrome study, ${ }^{(23)}$ patients with severe ARDS who were on MV were allocated to being placed in the prone position for at least 16 consecutive hours or to remaining in the traditional supine position. The authors found that 28-day and 90-day mortality rates were lower in the prone positioning group. A subsequent meta-analysis demonstrated that, if prone positioning during MV is used for periods longer than $16 \mathrm{~h}$ per day and in conjunction with protective MV, it significantly reduces mortality in patients with moderate or severe ARDS. (24)

There have been few studies evaluating the effects that the combination of prone positioning and HFOV have on oxygenation, lung inflammation, and histologically confirmed damage in experimental models of acute lung injury (ALI). (25) To our knowledge, there have been no studies evaluating the regionalization of lung injury regarding histology, lung inflammation, and oxidative stress.

The hypothesis of the present study is that prone positioning combined with HFOV improves oxygenation, as well as attenuating the lung injury caused by inflammation or oxidative stress. Therefore, the objective was to compare prone and supine positioning during HFOV, in terms of the effects they have on oxygenation, lung inflammation, histological lung injury, and oxidative stress, in a rabbit model of ALI.

\section{METHODS}

\section{Design, animals, and instrumentation}

This was a prospective, randomized, in vivo animal study. Thirty male Norfolk white rabbits, weighing 2.0$3.0 \mathrm{~kg}$, were obtained from the animal facilities of the São Paulo State University Botucatu School of Medicine. The rabbits were first anesthetized with intramuscular injections of ketamine $(50 \mathrm{mg} / \mathrm{kg})$ and xylazine $(4 \mathrm{mg} /$ $\mathrm{kg}) \cdot(26,27)$ Each rabbit was then ventilated with $100 \%$ inhaled oxygen during spontaneous breathing, after which the neck and thorax were shaved for placement of electrodes for heart rate monitoring. The anterior region of the neck was anesthetized with $2 \%$ lidocaine, a tracheotomy was performed, and a tracheal tube (3.0-3.5 mm diameter PORTEX tube; Smith Medical,
Hythe, England) was inserted. Immediately thereafter, ventilation was initiated with a ventilator (Galileo Gold; Hamilton Medical AG, Bonaduz, Switzerland) in pressure-regulated volume control mode with the following initial parameters: $\mathrm{FiO}_{2}=1.0 ; \mathrm{V}_{\mathrm{T}}=6 \mathrm{~mL} /$ $\mathrm{kg}$; $\mathrm{PEEP}=5 \mathrm{cmH}_{2} \mathrm{O}$; and $\mathrm{RR}=40-50$ breaths $/ \mathrm{min}$. A 22-gauge vascular catheter (Introcan Safety; B. Braun, Melsungen, Germany) was then inserted into the common carotid artery, and a 5-French double-lumen catheter (Arrow International Inc., Reading, PA, USA) was advanced into the superior vena cava through the jugular vein. The arterial catheter was used in order to assess blood gases and arterial blood pressures with a monitoring system (LogiCal; Medex, Dublin, OH, USA) connected to a conventional physiological monitor (DX 2010; Dixtal, Manaus, Brazil). The double-lumen catheter was used for the continuous intravenous infusion of ketamine ( $10 \mathrm{mg} / \mathrm{kg}$ per hour) and xylazine ( $4 \mathrm{mg} / \mathrm{kg}$ per hour). Muscle paralysis was induced by intravenous administration of pancuronium bromide $(0.2 \mathrm{mg} / \mathrm{kg})$ and maintained with $0.1 \mathrm{mg} / \mathrm{kg}$ doses, as needed, to minimize respiratory movements and avoid disproportionate tachycardia.

During the experiment, we used continuous intravenous infusion of norepinephrine $(0.5-1 \mu \mathrm{g} / \mathrm{kg}$ per minute) to keep the mean arterial pressure above $50 \mathrm{mmHg}$, as necessary. The need for inotropic support was determined through the use of a vasoactiveinotropic score. ${ }^{(28)}$ Fluid maintenance was provided by continuous infusion of $0.9 \%$ saline solution containing $5 \%$ dextrose at $4 \mathrm{~mL} / \mathrm{kg}$ per hour. Body temperature was monitored continuously by esophageal probe and was maintained at $38-39^{\circ} \mathrm{C}$ with electric warming pads. Continuous pulse oximetry was also performed.

The rabbits were handled with care to minimize discomfort, distress, and pain, in compliance with the Guide for the Care and Use of Laboratory Animals published by the US National Institute of Health (NIH Publication No. 85-23, 2011 revision). The study was approved by the Experimental Research and Ethics Committee of the Botucatu School of Medicine of São Paulo State University (Reference no. 795).

\section{Lung injury induction}

Lung injury was induced by surfactant lavage. ${ }^{(26,29)}$ In brief, six successive lung lavages were performed with heated saline $\left(37-38^{\circ} \mathrm{C}\right)$ in aliquots of $30 \mathrm{~mL} / \mathrm{kg}$, passed through the tracheal cannula at a maximum pressure of $30 \mathrm{cmH}_{2} \mathrm{O}$, for $60 \mathrm{~s}$, every 3-5 min. Drainage of the fluid was achieved by gravity, by external movements of thoracic compression, and by gentle suction. After stabilization, arterial blood samples were obtained for blood gas analysis to verify that animals were hypoxemic $\left(\mathrm{PaO}_{2} / \mathrm{FiO}_{2}\right.$ ratio $\leq 100 \mathrm{mmHg}$ in two analyses, $15 \mathrm{~min}$ apart). If the animals were still not hypoxemic, two additional lavages were performed sequentially, new blood gas analyses being performed 10 min thereafter, and so on, until the $\mathrm{PaO}_{2} / \mathrm{FiO}_{2}$ ratio reached the target value. After another stabilization period, animals were given two 30-s sustained inflations with a mean Paw of 
$30 \mathrm{cmH}_{2} \mathrm{O}$, a dynamic maneuver intended to promote lung recruitment and normalize the volume history. ${ }^{(30)}$

\section{Experimental groups}

Using the Research Randomizer program (available at http://www.randomizer.org), we randomly divided the rabbits into two groups: ALI+HFOV in the supine position (SP group, $\mathrm{n}=15$ ); and ALI+HFOV with prone positioning (PP group, $n=15$ ). At the start of the experimental period, we ventilated the animals in both groups with a SensorMedics 3100A ventilator (CareFusion, Yorba Linda, CA, USA), using the following parameters: mean Paw of $16 \mathrm{cmH}_{2} \mathrm{O}$; oscillatory frequency of $10 \mathrm{~Hz}$; inspiratory time of $33 \%$ of the respiratory cycle; and initial pressure amplitude of $20 \mathrm{cmH}_{2} \mathrm{O}$. The pressure amplitude was modified to reach the target $\mathrm{PaCO}_{2}$ range $(40-45 \mathrm{mmHg})$. In both groups, the $\mathrm{FiO}_{2}$ was maintained at 1.0 throughout the experiment.

After a 15-min stabilization period, the animals were moved into the prone position or maintained in the supine position, according to the randomization. That was designated time zero $\left(T_{0}\right)$ of the experimental protocol. At $30 \mathrm{~min}, 60 \mathrm{~min}$, and $90 \mathrm{~min}$ thereafter $\left(\mathrm{T}_{30}, \mathrm{~T}_{60}\right.$, and $\mathrm{T}_{90}$, respectively), the mean Paw was decreased to 14,12 , and $10 \mathrm{cmH}_{2} \mathrm{O}$, respectively, to avoid hemodynamic instability. At $120 \mathrm{~min}\left(\mathrm{~T}_{120}\right)$, all animals were returned to or remained in the supine position and were ventilated for an additional $30 \mathrm{~min}$ (i.e., until $T_{150}$ ). Arterial blood samples, for blood gas analysis, were obtained at baseline, after the induction of lung injury, and every 30 min throughout the 150-min observation period. Blood gas analyses were performed at the corresponding time points (baseline, ALI confirmed, $\mathrm{T}_{30}, \mathrm{~T}_{60}, \mathrm{~T}_{90}, \mathrm{~T}_{120}$, and $\mathrm{T}_{150}$ ), as shown in Figure 1.
In accordance with other studies using a similar methodology, we chose to include 15 animals in each group. ${ }^{(26,29)}$ Rabbits that died before $T_{150}$ were replaced. During the experimental period, the groups were compared regarding the mean arterial pressure (to evaluate hemodynamic stability); the $\mathrm{PaO}_{2} / \mathrm{FiO}_{2}$ ratio; and the oxygenation index $-[\mathrm{FiO} 2 \times$ mean $\mathrm{Paw}]$ / $\mathrm{PaO} 2 \times 100$-expressed in $\mathrm{cmH}_{2} \mathrm{O} / \mathrm{mmHg}$. At $\mathrm{T}_{150}$ / the rabbits were euthanized through the administration of high intravenous doses of ketamine and xylazine. The following outcome measures were then evaluated: malondialdehyde concentrations (lipid peroxidation), to quantify oxidative stress in ventral and dorsal lung tissue; proportions of neutrophils in the BAL fluid (BALF); TNF-a levels in the BALF and in lung tissue, to quantify lung inflammation; and histopathological analysis, to quantify lung tissue damage.

\section{Tissue collection}

The right lung was dissected and stored for oxidative stress analysis, and the left lung was dissected for BAL. Tissue specimens for oxidative stress study were snap-frozen in liquid nitrogen and stored at $-80^{\circ} \mathrm{C}$ until analysis, as previously described. ${ }^{(26,27)}$

\section{$B A L$}

The BALF was collected, and the cells were counted in a hemocytometer. Cells were differentiated using a Romanowsky-type stain (Panótico Rápido; Laborclin, Pinhais, Brazil), and the proportion of neutrophils was assessed.

\section{TNF-a measurement}

Levels of TNF-a were measured in the BALF and lung tissue homogenates with a radioimmunoassay technique, as reported elsewhere. ${ }^{(31)}$ The standards

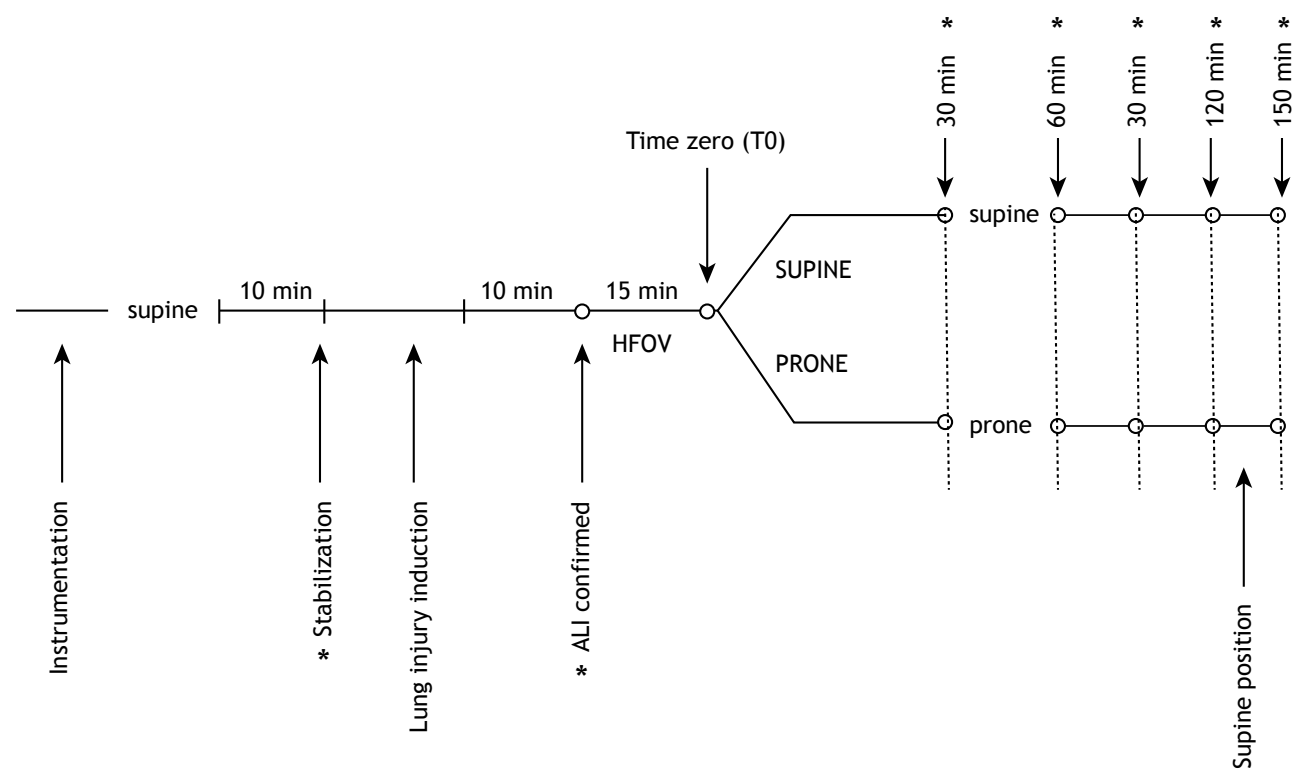

Figure 1. Experimental protocol design. ALI: acute lung injury; and HFOV: high-frequency oscillatory ventilation. *Arterial blood gas analysis. 
used were a specific antiserum to human TNF-a (Caltag Laboratories, South San Francisco, CA, USA) at a dilution of $1: 100,000$; radiolabeled human TNF-a (New England Nuclear, Boston, MA, USA); and purified human TNF-a (Collaborative Research, Bedford, MA, USA).

\section{Lipid peroxidation measurement}

Concentrations of malondialdehyde, a marker of lipid oxidative damage, were measured in tissue homogenates by using the method devised by Esterbauer and Cheeseman. ${ }^{(32)}$ Lung tissue was homogenized with $20 \mathrm{mM}$ ice-cold Tris- $\mathrm{HCl}$ buffer, $\mathrm{pH}$ 7.4 , at a ratio of $1 \mathrm{~g}$ of tissue to $10 \mathrm{~mL}$ of buffer. The homogenate was centrifuged at $3,000 \times g$ at $4^{\circ} \mathrm{C}$ for $10 \mathrm{~min}$. The supernatant $(200 \mu \mathrm{L})$ was set aside and mixed with a solution containing methanol and 10.3 $\mathrm{mM} \mathrm{N}$-methyl-2-phenylindole, in acetonitrile $(650 \mu \mathrm{L}$; Oxis International, Portland, OR, USA). The solution was acidified with $37 \%$ hydrochloric acid $(150 \mu \mathrm{L})$ and incubated at $45^{\circ} \mathrm{C}$ for $60 \mathrm{~min}$. Samples were again centrifuged as described above, to clarify any precipitate formed during incubation. Absorbance was measured with a spectrophotometer (DU 650; Beckman Coulter, Carlsbad, CA, USA) at $586 \mathrm{~nm}$, against standard curves of 1,1,3,3-tetramethoxypropane and 4-hydroxynonenal diacetyl (Oxis International). Lung tissue measurements were indexed to lung tissue protein content.

\section{Histopathological analysis}

Lungs were filled with $10 \%$ buffered formalin, by gravity (at a maximum pressure of $30 \mathrm{cmH}_{2} \mathrm{O}$ ), to preserve the alveolar architecture. At least $48 \mathrm{~h}$ after fixation, fragments were embedded in paraffin. Axial lung sections were cut, stained with $\mathrm{H} \& \mathrm{E}$, and examined by two pathologists who were blinded to the groups and worked independently. For each slide, we randomly selected ten microscopic fields for examination, thus performing 20 tests per animal. Pulmonary histological damage was quantified by a score that involved seven variables: alveolar inflammation; interstitial inflammation; alveolar hemorrhage; interstitial hemorrhage; edema; atelectasis; and necrosis. For each of those seven variables, the severity was graded as follows: $0=$ no injury; $1=$ injury in $25 \%$ of the field; $2=$ injury in $50 \%$ of the field; $3=$ injury in $75 \%$ of the field; and $4=$ diffuse injury. Therefore, the maximum possible score was $28 .{ }^{(33)}$

\section{Statistical analysis}

Data were analyzed with SigmaPlot, version 11.0 for Windows (Systat Software, San Jose, CA, USA). Normally distributed data were compared between the groups for the same time points by t-test or across time points by Kruskal-Wallis one-way ANOVA and are expressed as mean \pm standard deviation. Data with non-normal distribution were compared by the Mann-Whitney rank-sum test and are expressed as median (range). Intragroup comparisons at different time points were performed using Friedman's repeated measures ANOVA by ranks, all pairwise multiple comparison procedures being performed by Dunn's test. Contingency tables of categorical data were compared by Fisher's exact test. Tissue analyses among groups and lung injury regions were performed through two-way ANOVA. Values of $p$ $\leq 0.05$ were considered statistically significant.

\section{RESULTS}

There was no statistical difference between the two groups in terms of body weight $(p=0.50)$ or the number of lavages required in order to induce ALI ( $p$ $=0.75$ ). The proportion of fluid recovered from the lavaged lungs was $85.7 \%$ and $86.2 \%$ in the PP and SP groups, respectively ( $p=0.49)$.

There was no statistical difference in mean arterial pressure between the two groups. The animals in both groups were hemodynamically stable, the mean arterial pressure remaining above $50 \mathrm{mmHg}$ due to the continuous infusion of norepinephrine, with no difference between the SP and PP groups in terms of the median vasoactive-inotropic score, which was 50 (range, 0-70) and 50 (range, 0-50), respectively ( $p=$ 0.27 ). There were three deaths during the experimental period, all of them in the SP group.

After the lavages, there was significant hypoxemia, decreased respiratory system compliance, and increased the mean Paw in the animals in both groups (Table 1), the successful induction of ALI thus being confirmed. At $\mathrm{T}_{30}$, both groups showed significant improvement in oxygenation, presenting oxygenation indices similar to those seen at baseline, those indices remaining stable until $\mathrm{T}_{150}$ (Figure 2).

The median malondialdehyde concentrations did not differ between the PP and SP groups, whether measured in ventral lung tissue samples $-8.2 \mathrm{~nm}$ (range, 7.7-11.4 $\mathrm{nm}$ ) and $8.7 \mathrm{~nm}$ (range, 5.7-13.6 $\mathrm{nm})$, respectively ( $\mathrm{p}=0.62$ )-or in dorsal lung tissue samples-7.4 nm (range, 5.9-0.8 nm) and $8.1 \mathrm{~nm}$ (range, $7.1-9.5 \mathrm{~nm})$, respectively $(\mathrm{p}=0.62)$. The mean proportion of neutrophils in the BALF was lower in the PP group than in the SP group ( $16 \pm 14$ vs. 25 \pm 18 ), although the difference was not significant ( $p$ $=0.76$ ). However, the TNF-a levels in the BALF and lung tissue were significantly lower in the PP group than in the SP group (Figure 3), and that difference was greater in the dorsal lung tissue samples. The histological lung injury score was also significantly lower in the PP group than in the SP group (Figure 4).

\section{DISCUSSION}

The results of the present study support those of previous studies, namely, that HFOV per se improves oxygenation and has a protective effect against histological and inflammatory lung injury. In addition, when HFOV was combined with prone positioning in this animal model of ALI, we observed better protection against the inflammatory response, as evaluated by determining TNF-a levels, as well as lower histological injury scores. Despite the lower 
Table 1. Oxygenation indices, pulmonary mechanics, and hemodynamic data, at baseline and after induction of lung injury. ${ }^{a}$

\begin{tabular}{lcccc}
\multicolumn{1}{c}{ Parameter } & \multicolumn{2}{c}{ Supine position } & \multicolumn{2}{c}{ Proup } \\
& Baseline & After lung injury & Baseline & After lung injury \\
\hline $\mathrm{PaO} 2 / \mathrm{FiO2}(\mathrm{mmHg})$ & $447.6(364.18-492.75)$ & $72.1(52.08-86.18)^{*}$ & $481.7(428.37-493.88)$ & $64.5(48.25-81.88)^{*}$ \\
$\mathrm{Olb}(\mathrm{cmH} 2 \mathrm{~m} / \mathrm{mmHg})$ & $1.5(1.41-2.06)$ & $13.7(11.21-21.15)^{*}$ & $1.44(1.38-1.74)$ & $14.7(11.8-21.26)^{*}$ \\
$\mathrm{Crs}(\mathrm{mL} / \mathrm{cmH} 20)$ & $3.3(3.1-3.68)$ & $1.2(1.0-1.3)^{*}$ & $3.8(2.83-4.4)$ & $1.2(1.0-1.38)^{*}$ \\
Mean Paw $(\mathrm{cmH} 20)$ & $7.0(6.9-7.1)$ & $10.0(9.5-11.0)^{*}$ & $7.04 \pm 0.5$ & $9.75 \pm 0.63^{*}$ \\
\hline
\end{tabular}

OI: oxygenation index; Crs: respiratory system compliance; and Paw: airway pressure. ${ }^{\mathrm{a}}$ Results expressed as mean \pm SD for data with normal distribution and as median (range) for data with non-normal distribution. ${ }^{b}$ Calculated as [FiO2 $\times$ mean Paw] / PaO2 $\times 100 . * \mathrm{p}<0.05$ vs. after lung injury; Kruskal-Wallis one-way ANOVA for data with normal distribution and Mann-Whitney rank-sum test for data with non-normal distribution.

(A)
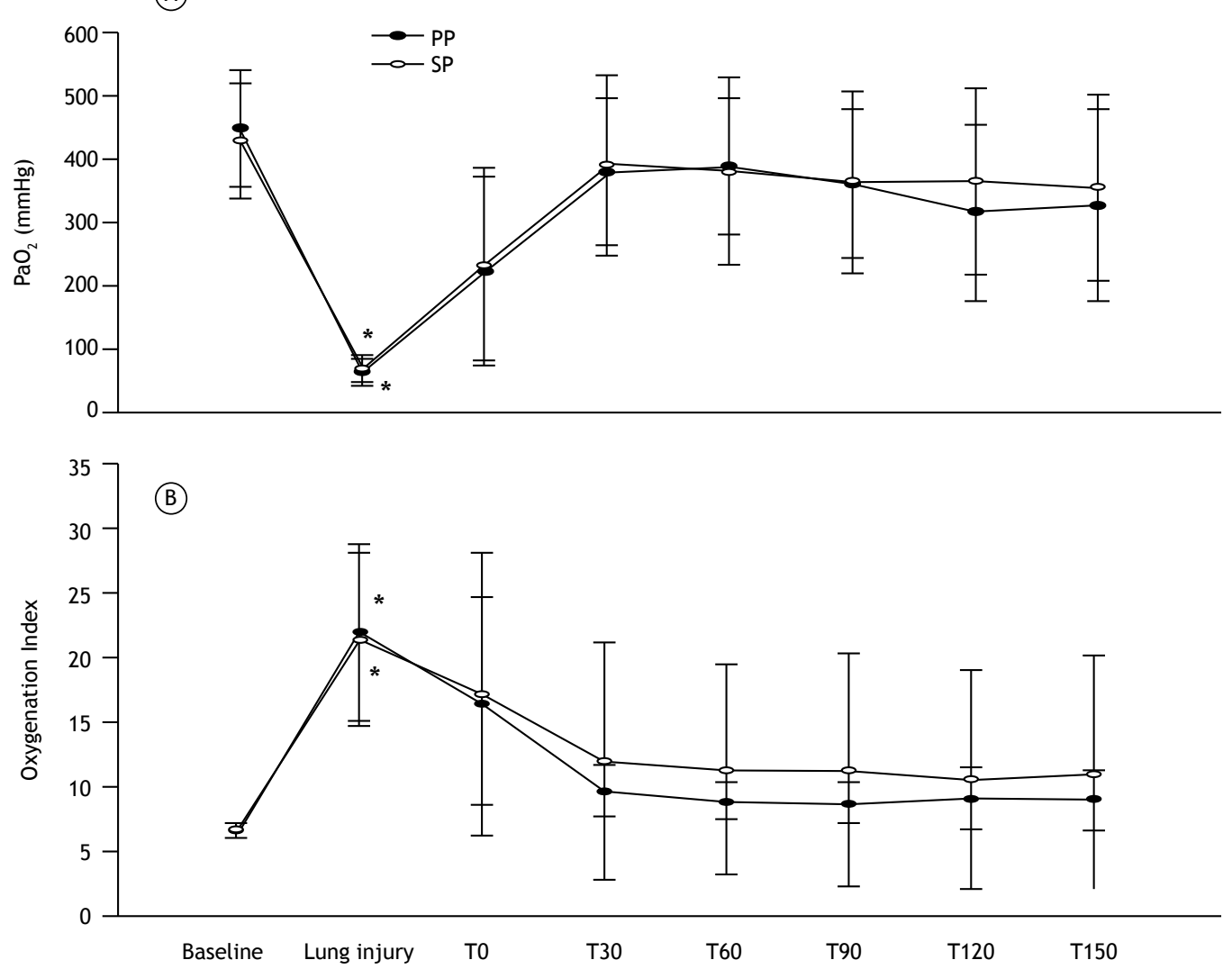

Figure 2. $\mathrm{PaO}_{2}$ and oxygenation index over time ( $\mathrm{A}$ and $\mathrm{B}$, respectively) in the experimental groups. ${ }^{\mathrm{b}} \mathrm{PP}$ : prone position group (filled ovals); SP: supine position group (open ovals); $T_{0}$ : time zero; $T_{30}: 30 \mathrm{~min} ; T_{60}: 60 \mathrm{~min} ; T_{90}: 90 \mathrm{~min} ; T_{120}$ : $120 \mathrm{~min}$; and $\mathrm{T}_{150}$ : $150 \mathrm{~min}$. aCalculated as $[\mathrm{FiO} 2 \times$ mean Paw $] / \mathrm{PaO} 2 \times 100$. bValues expressed as mean $\pm \mathrm{SD}$. *p $\leq$ 0.05 vs. baseline.

numbers of inflammatory cells in the BALF in the PP group, the difference in comparison with the SP group was not significant.

It has been known for decades that prone positioning improves oxygenation in animal models of lung injury and in patients with severe ARDS. The mechanisms of that improvement include a more uniform pleuralpressure gradient and less compression of the lung by the heart, as well as more uniform distribution and better matching of ventilation and perfusion. ${ }^{(34)}$ In addition to those physiological effects, we found that, in the prone position, there were structural changes within the lungs; that is, the dorsal lung areas were preserved regarding histological and inflammatory injury.

A previous study performed by our group showed that HFOV plays a major protective role in ALI, improving oxygenation, minimizing inflammatory processes, reducing histological damage, and attenuating oxidative lung injury, proving superior to protective CMV in those aspects. ${ }^{(29)}$ Likewise, a study conducted by Liu et al. ${ }^{(35)}$ showed that HFOV at a relatively high oscillatory frequency attenuated lung injury in an ovine model of ARDS. In that study, HFOV at an oscillatory frequency of $9 \mathrm{~Hz}$ minimized lung stress and $\mathrm{V}_{\mathrm{T}}$, resulting in less lung injury and lower levels of inflammatory mediators 
(A)

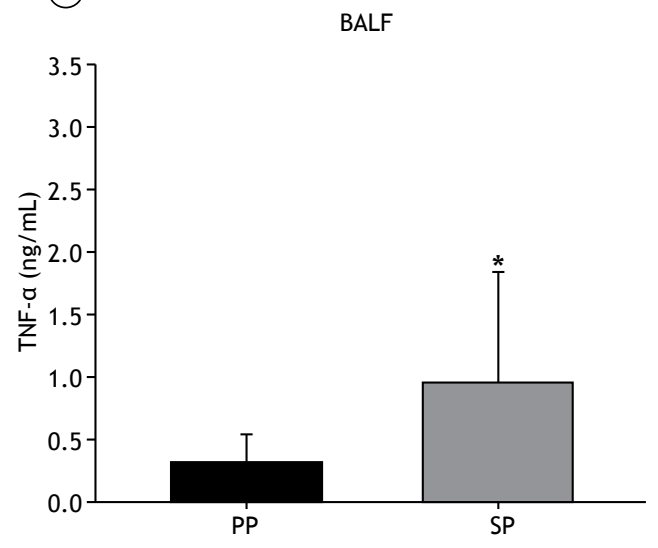

(B)

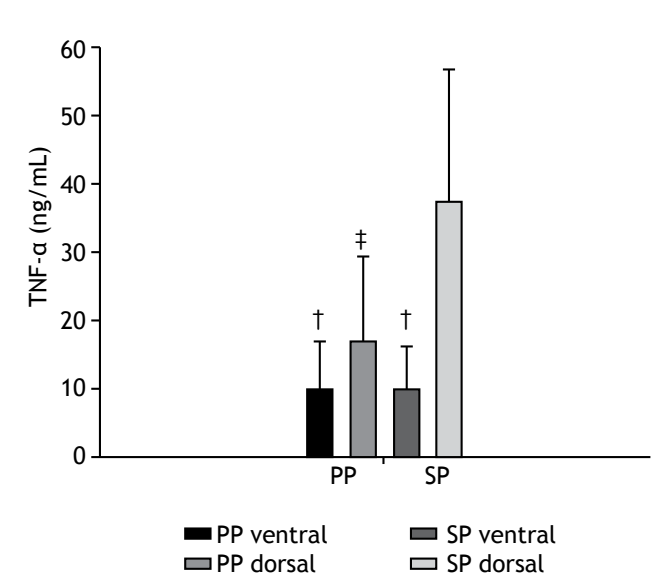

Figure 3. TNF-a levels in BAL fluid (BALF) and lung tissue (A and B, respectively), ${ }^{\text {a }}$ the latter comparing ventral and dorsal lung tissue samples, in the prone position (PP) and supine position (SP) groups. avalues expressed as mean \pm SD. ${ }^{*} p \leq 0.05$ vs. PP group. ${ }^{+} p>0.05$ vs. dorsal lung tissue in the PP group. ${ }^{\ddagger} p \leq 0.05$ vs. dorsal lung tissue in the SP group.

Histological lung injury

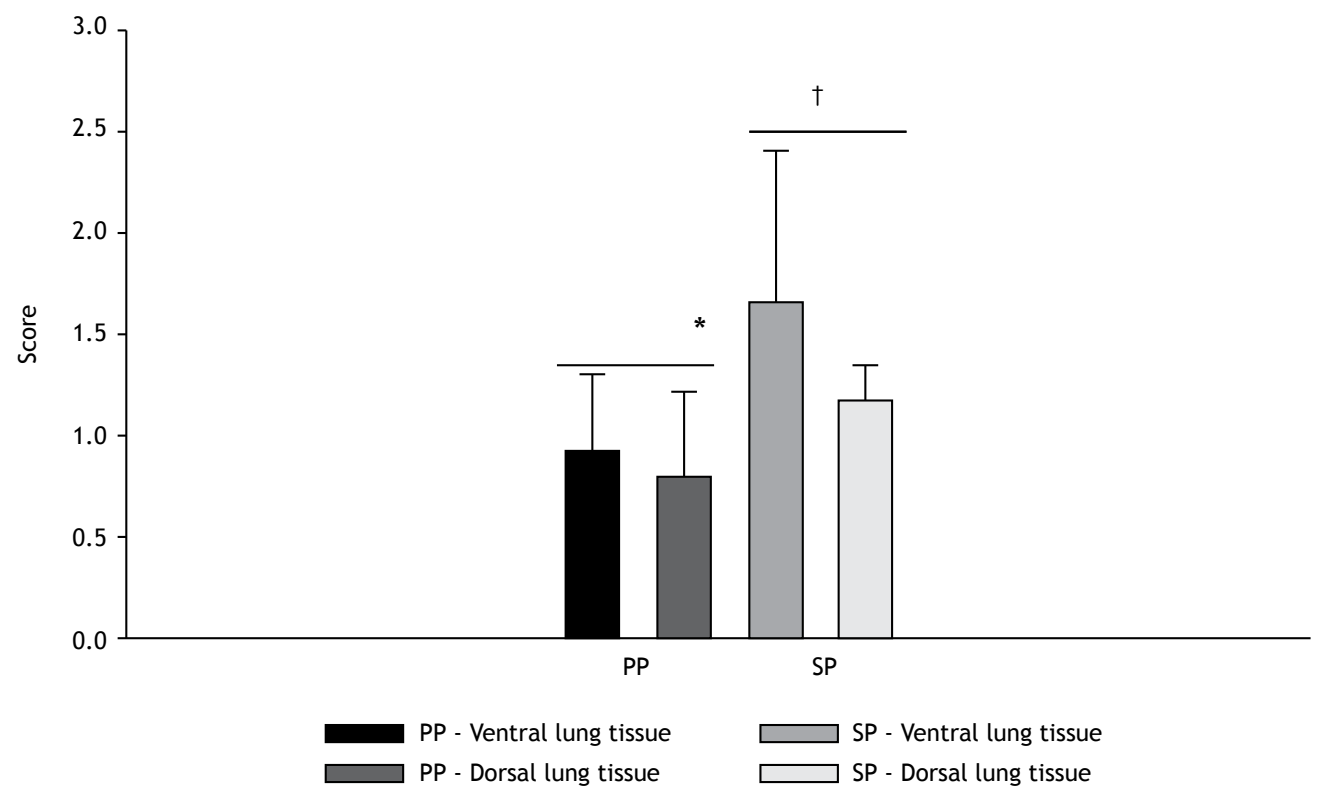

Figure 4. Histological lung injury scores in the supine position (SP) and prone position (PP) groups, including comparisons between scores for ventral and dorsal lung tissue samples. ${ }^{a, \neq}$ avalues expressed as median (range). ${ }^{*} p<0.05$ vs. ventral lung tissue (Mann-Whitney rank-sum test). ${ }^{\dagger} p<0.05$ vs. PP group (Mann-Whitney rank-sum test). ${ }^{\neq} p>0.05$ for interactions among lung regions and positioning (Kruskal-Wallis ANOVA, followed by Dunn's test).

than those observed when HFOV at an oscillatory frequency of $3 \mathrm{~Hz}$ or CMV was employed.

In a prospective randomized clinical study involving patients with $A R D S,{ }^{(36)}$ the authors analyzed oxygenation by calculating the $\mathrm{PaO}_{2} / \mathrm{FiO}_{2}$ ratio and oxygenation index, analyzing lung inflammation by determining serum and BALF levels of cytokines, as well as by cytological examination of the BALF cytology. The authors concluded that prone positioning during CMV or HFOV improved oxygenation in comparison with supine positioning throughout HFOV. In addition, they found that prone positioning during HFOV reduced serum levels of IL-8 and the proportion of neutrophils in the BALF, indicating decreased lung inflammation. Those data were confirmed by our findings, which showed that, in the dorsal lung tissue, the inflammatory response, as evaluated by determining TNF-a levels, was less pronounced in the PP group than in the SP group.

In the present study, the proportion of neutrophils in the BALF did not differ significantly between the 
two groups, although there was a trend toward lower values in the PP group. It is possible that the proportion of neutrophils was higher in the SP group because of greater damage occurring in the dorsal lung tissue during ALI induction. That suggests that prone positioning was protective against inflammatory lung injury. The fact that our findings did not reach statistical significance was likely due to the short MV period. Regarding the assessment of lung inflammation, we found that TNF-a levels in the BALF were lower, probably indicating less inflammatory injury, in the PP group than in the SP group, as were TNF-a levels in homogenates of lung tissue samples from the ventral and dorsal regions. However, TNF-a values for the ventral and dorsal regions were comparable within the PP group. Similar results were observed by Fu et al., ${ }^{(37)}$ who induced ALI in newborn piglets that were subsequently ventilated for $24 \mathrm{~h}$. The authors observed that, among the piglets with ALI, histological lung injury was more severe in the gravity-dependent region than in the non-gravity-dependent region, as well as that different ventilation strategies resulted in different effects on the injured lungs. Despite improving oxygenation, HFOV with a high lung volume strategy was found to attenuate lung injury by reducing pulmonary infiltration by polymorphonuclear cells, hemorrhage, alveolar edema, and hyaline membrane formation, to a greater degree than did CMV. ${ }^{(37)}$

In a study involving patients with severe communityacquired pneumonia and ARDS on protective CMV, Chan et al ${ }^{(38)}$ showed that oxygenation was better and levels of IL- 6 were significantly lower in the patients who were ventilated in the prone position than in those who were ventilated in the supine position. Similarly, in an early study of ARDS, Rival et al. ${ }^{(39)}$ found that a recruitment maneuver and prone positioning probably have combined effects, as well as showing that the recruitment maneuver probably improved $\mathrm{PaO}_{2}$ to a greater degree when the patients were in the prone position, especially if they remained in that position for an extended period of time.

Our study has some limitations. One is the fact that it was an experimental study, given that animal models cannot replicate all of the characteristics of ALI/ARDS in humans. ${ }^{(40)}$ In addition, because of the risk of hemodynamic instability, ventilation time is limited in rabbit models of ALI. In the present study, rabbits were ventilated for only two hours, and it was therefore difficult to apply the ideal HFOV and time in the prone position to achieve the anti-inflammatory effect and decrease the lesion. Furthermore, we evaluated prone positioning only during HFOV. There is a need for longer-term studies involving groups of healthy, nonventilated animals (controls) and groups of animals ventilated with CMV, as well as for clinical studies evaluating outcomes in patients treated with these combination strategies.

In conclusion, our findings corroborate those of previous studies showing that HFOV improves oxygenation and has a protective effect against the inflammatory response and histological lung damage in models of lung injury. In addition, our data underscore the major protective role played by prone positioning. In this model of ALI in rabbits subsequently undergoing HFOV, in which we compared gravity-dependent and non-gravity-dependent lung regions, prone positioning was found to minimize inflammatory processes and histological damage.

\section{ACKNOWLEDGMENTS}

We thank the staff of the Experimental Laboratory of the Universidade Estadual Paulista (UNESP, São Paulo State University) Department of Pediatrics, for their assistance.

\section{REFERENCES}

1. ARDS Definition Task Force, Ranieri VM, Rubenfeld GD, Thompson $B T$, Ferguson ND, Caldwell $E$, et al. Acute respiratory distress syndrome: the Berlin Definition. JAMA. 2012;307(23):2526-33.

2. MacCallum NS, Evans TW. Epidemiology of acute lung injury. Curr Opin Crit Care. 2005;11(1):43-9. https://doi.org/10.1097/00075198200502000-00007

3. de Hemptinne Q, Remmelink M, Brimioulle S, Salmon I, Vincent JL. ARDS: a clinicopathological confrontation. Chest. 2009;135(4):944949. https://doi.org/10.1378/chest.08-1741

4. Herridge MS, Cheung AM, Tansey CM, Matte-Martyn A, DiazGranados N, Al-Saidi F, et al. One-year outcomes in survivors of the acute respiratory distress syndrome. N Engl J Med. 2003;348(8):68393. https://doi.org/10.1056/NEJMoa022450

5. Cheung AM, Tansey CM, Tomlinson G, Diaz-Granados N, Matté A, Barr A, et al. Two-year outcomes, health care use, and costs of survivors of acute respiratory distress syndrome. Am J Respir Crit Care Med. 2006;174(5):538-44. https://doi.org/10.1164/ rccm.200505-6930C

6. Fioretto JR, Batista KA, Carpi MF, Bonatto RC, Moraes MA, Ricchetti $\mathrm{SM}$, et al. High-frequency oscillatory ventilation associated with inhaled nitric oxide compared to pressure-controlled assist/control ventilation and inhaled nitric oxide in children: Randomized, nonblinded, crossover study. Pediatr Pulmonol. 2011;46(8):809-16. https://doi.org/10.1002/ppul.21452

7. Amato MB, Meade MO, Slutsky AS, Brochard L, Costa EL,
Schoenfeld DA, et al. Driving pressure and survival in the acute respiratory distress syndrome. N Engl J Med. 2015;372(8):747-55 https://doi.org/10.1056/NEJMsa1410639

8. Turner DA, Arnold JH. Insights in pediatric ventilation: timing of intubation, ventilatory strategies, and weaning. Curr Opin Crit Care. 2007;13(1):57-63. https://doi.org/10.1097/MCC.0b013e32801297f9

9. Girard TD, Bernard GR. Mechanical ventilation in ARDS: a state-ofthe-art review. Chest. 2007;131(3):921-929. https://doi.org/10.1378/ chest.06-1515

10. Fioretto JR, Rebello CM. High-frequency oscillatory ventilation in pediatrics and neonatology. Rev Bras Ter Intensiva. 2009;21(1):96103. https://doi.org/10.1590/S0103-507X2009000100014

11. Chan KP, Stewart TE, Mehta S. High-frequency oscillatory ventilation for adult patients with ARDS. Chest. 2007;131(6):1907-16. https:// doi.org/10.1378/chest.06-1549

12. Ferguson ND, Cook DJ, Guyatt GH, Mehta S, Hand L, Austin P et al. High-frequency oscillation in early acute respiratory distress syndrome. N Engl J Med. 2013;368(9):795-805. https://doi. org/10.1056/NEJMoa1215554

13. Meade MO, Young D, Hanna S, Zhou Q, Bachman TE, Bollen C, et al. Severity of Hypoxemia and Effect of High-Frequency Oscillatory Ventilation in Acute Respiratory Distress Syndrome. Am J Respir Crit Care Med. 2017;196(6):727-733. https://doi.org/10.1164/ rccm.201609-19380C

14. Goligher EC, Munshi L, Adhikari NKJ, Meade MO, Hodgson CL, 
Wunsch $\mathrm{H}$, et al. High-Frequency Oscillation for Adult Patients with Acute Respiratory Distress Syndrome:A Aystematic Reviewand MetaAnalysis. Ann Am Thorac Soc. 2017;14(Supplement_4):S289-S296.

15. Cakar N, der Kloot TV, Youngblood M, Adams A, Nahum A Oxygenation response to a recruitment maneuver during supine and prone positions in an oleic acid-induced lung injury model. Am J Respir Crit Care Med. 2000;161(6):1949-56. https://doi.org/10.1164/ ajrccm.161.6.9907113

16. Pelosi $P$, Brazzi $L$, Gattinoni $L$. Prone position in acute respiratory distress syndrome. Eur Respir J. 2002;20(4):1017-28. https://doi.or $\mathrm{g} / 10.1183 / 09031936.02 .00401702$

17. Richard JC, Janier M, Lavenne F, Berthier V, Lebars D, Annat G, et al. Effect of position, nitric oxide, and almitrine on lung perfusion in a porcine model of acute lung injury. J Appl Physiol (1985). 2002;93(6):2181-91. https://doi.org/10.1152/japplphysiol.00313.2002

18. Pelosi $P$, Tubiolo D, Mascheroni D, Vicardi $P$, Crotti $S$, Valenza $F$ et al. Effects of the prone position on respiratory mechanics and gas exchange during acute lung injury. Am J Respir Crit Care Med. 1998;157(2):387-93. https://doi.org/10.1164/ajrccm.157.2.97-04023

19. Galiatsou E, Kostanti E, Svarna E, Kitsakos A, Koulouras V, Efremidis $\mathrm{SC}$, et al. Prone position augments recruitment and prevents alveolar overinflation in acute lung injury. Am J Respir Crit Care Med. 2006;174(2):187-97. https://doi.org/10.1164/rccm.200506-8990C

20. Gattinoni L, Protti A. Ventilation in the prone position: for some but not for all? CMAJ. 2008;178(9):1174-6. https://doi.org/10.1503/ cmaj.080359

21. Albert RK, Hubmayr RD. The prone position eliminates compression of the lungs by the heart. Am J Respir Crit Care Med. 2000;161(5):1660-5. https://doi.org/10.1164/ajrccm.161.5.9901037

22. Gillart T, Bazin JE, Guelon D, Constantin JM, Mansoor O, Conio N, et al. Effect of bronchial drainage on the improvement in gas exchange observed in ventral decubitus in ARDS [Article in French]. Ann Fr Anesth Reanim. 2000;19(3):156-63. https://doi.org/10.1016/S07507658(00)00199-4

23. Guérin $C$, Reignier J, Richard JC, Beuret P, Gacouin A, Boulain T, et al. Prone positioning in severe acute respiratory distress syndrome N Engl J Med. 2013;368(23):2159-68. https://doi.org/10.1056/ NEJMoa1214103

24. Sud S, Friederich JO, Adhikari NK, Taccone P, Mancebo J, Polli F, et al. Effect of prone positioning during mechanical ventilation on mortality among patients with acute respiratory distress syndrome: a systematic review and meta-analysis. CMAJ. 2014;186(10):E381-90 https://doi.org/10.1503/cmaj.14008

25. Brederlau J, Muellenbach R, Kredel M, Greim C, Roewer N. High frequency oscillatory ventilation and prone positioning in a porcine model of lavage-induced acute lung injury. BMC Anesthesiol. 2006;6:4. https://doi.org/10.1186/1471-2253-6-4

26. Ronchi CF, Fioretto JR, Ferreira AL, Berchieri-Ronchi CB, Correa $\mathrm{CR}$, Kurokawa CS, et al. Biomarkers for oxidative stress in acute lung injury induced in rabbits submitted to different strategies of mechanical ventilation. J Appl Physiol (1985). 2012:112(7):1184-90. https://doi.org/10.1152/japplphysiol.01334.2011

27. Ronchi CF, Ferreira AL, Campos FJ, Kurokawa CS, Carpi MF, Moraes MA, et al. Interactive effects of mechanical ventilation, inhaled nitric oxide and oxidative stress in acute lung injury. Respir Physiol Neurobiol. 2014;190:118-23. https://doi.org/10.1016/j. resp.2013.10.008

28. Gaies MG, Gurney JG, Yen AH, Napoli ML, Gajarski RJ, Ohye RG, et al Vasoactive-inotropic score as a predictor of morbidity and mortality in infants after cardiopulmonary bypass. Pediatr Crit Care Med. 2010;11(2):234-8. https://doi.org/10.1097/PCC.0b013e3181b806fc

29. Ronchi CF, dos Anjos Ferreira AL, Campos FJ, Kurokawa CS, Carp $M F$, de Moraes MA, et al. High-frequency oscillatory ventilation attenuates oxidative lung injury in a rabbit model of acute lung injury. Exp Biol Med (Maywood). 2011;236(10):1188-96. https://doi. org/10.1258/ebm.2011.011085

30. McCulloch PR, Forkert PG, Froese AB. Lung volume maintenance prevents lung injury during high frequency oscillatory ventilation in surfactant-deficient rabbits. Am Rev Respir Dis. 1988;137(5):118592. https://doi.org/10.1164/ajrccm/137.5.1185

31. Coalson JJ, Winter VT, Siler-Khodr T, Yoder BA. Neonatal chronic lung disease in extremely immature baboons. Am J Respir Crit Care Med. 1999;160(4):1333-46. https://doi.org/10.1164/ajrccm.160.4.9810071

32. Esterbauer $\mathrm{H}$, Cheeseman KH. Determination of aldehydic lipid peroxidation products: malonaldehyde and 4-hydroxynonenal. Methods Enzymol. 1990;186:407-21. https://doi.org/10.1016/00766879(90)86134-H

33. Rotta AT, Gunnarsson B, Hernan LJ, Fuhrman BP, Steinhorn DM Partial liquid ventilation influences pulmonary histopathology in an animal model of acute lung injury. J Crit Care. 1999;14(2):84-92. https://doi.org/10.1016/S0883-9441(99)90019-9

34. Fessler HE, Talmor DS. Should prone positioning be routinely used for lung protection during mechanical ventilation? Respir Care. 2010;55(1):88-99.

35. Liu S, Yi Y, Wang M, Chen Q, Huang Y, Liu L, et al. Higher frequency ventilation attenuates lung injury during high-frequency oscillatory ventilation in sheep models of acute respiratory distress syndrome. Anesthesiology. 2013;119(2):398-411. https://doi.org/10.1097/ ALN.0b013e31829419a6

36. Papazian L, Gainnier M, Marin V, Donati S, Arnal JM, Demory D, et al. Comparison of prone positioning and high-frequency oscillatory ventilation in patients with acute respiratory distress syndrome Crit Care Med. 2005;33(10):2162-71. https://doi.org/10.1097/01. CCM.0000181298.05474.2B

37. Fu W, Qin $X$, You $C$, Meng $Q$, Zhao $Y$, Zhang $Y$. High frequency oscillatory ventilation versus conventional ventilation in a newborn piglet model with acute lung injury. Respir Care. 2013;58(5):824-30.

38. Chan MC, Hsu JY, Liu HH, Lee YL, Pong SC, Chang LY, et al. Effects of prone position on inflammatory markers in patients with ARDS due to community-acquired pneumonia. J Formos Med Assoc. 2007;106(9):708-16. https://doi.org/10.1016/S0929-6646(08)60032-7

39. Rival G, Patry C, Floret N, Navellou JC, Belle E, Capellier G. Prone position and recruitment manoeuvre: the combined effect improves oxygenation. Crit Care. 2011;15(3):R125. https://doi.org/10.1186/ cc10235

40. Wang HM, Bodenstein M, Markstaller K. Overview of the pathology of three widely used animal models of acute lung injury. Eur Surg Res 2008;40(4):305-16. https://doi.org/10.1159/000121471 